\title{
Human adipose triglyceride lipase (PNPLA2) is not regulated by obesity and exhibits low in vitro triglyceride hydrolase activity
}

Received: 14 February 2006 / Accepted: 7 March 2006 / Published online: 10 May 2006

C) Springer-Verlag 2006

\begin{abstract}
Aims/hypothesis: The recent identification of murine adipose triglyceride lipase (ATGL, now known as patatin-like phospholipase domain containing 2 [PNPLA2]), gene product of Pnpla2, has questioned the unique role of hormone sensitive lipase (HSL, now known as LIPE), gene product of Lipe, in fat cell lipolysis. Here, we investigated human $A T G L$ and $H S L$ adipose tissue gene expression and in vitro lipase activity. Subjects, materials and methods: Levels of mRNA in adipose tissue from healthy obese and non-obese subjects were measured and lipase activity and adipocyte lipolytic capacity determined. $H S L$ and $A T G L$ cDNAs were transfected into Cos-7 cells and the relative tri- and diglyceride hydrolase activities were measured. Results: Obesity was associated with a decreased subcutaneous and increased omental adipose tissue level of $H S L$ mRNA. Subcutaneous HSL mRNA content was normalised upon weight reduction. In contrast, $A T G L$ mRNA levels were unaffected by obesity and weight reduction. A high adipose tissue lipase activity was associated with increased maximal lipolysis and increased $H S L$, but not with $A T G L$ mRNA levels. The in vitro triglyceride hydrolase activity of HSL was markedly higher than that of ATGL and contrary to HSL, ATGL was devoid of diglyceride hydrolase activity. The use of a
\end{abstract}

\author{
A. Mairal · D. Langin \\ Inserm, U586, Obesity Research Unit, \\ Toulouse, France \\ A. Mairal · D. Langin \\ Paul Sabatier University, Louis Bugnard Institute IFR31, \\ Toulouse, France \\ D. Langin \\ Toulouse University Hospital, \\ Toulouse, France \\ P. Arner $\cdot$ J. Hoffstedt $(\bowtie)$ \\ Department of Medicine, Karolinska Institutet, \\ Karolinska University Hospital Huddinge, \\ 14186 Stockholm, Sweden \\ e-mail: johan.hoffstedt@ki.se \\ Tel.: +46-858582312 \\ Fax: $+46-858582407$
}

selective HSL-inhibitor resulted in complete inhibition of HSL-mediated tri- and diglyceride hydrolase activity. The $\mathrm{pH}$ profile of human white adipose tissue triolein hydrolase activity was identical to that of HSL but differed from the ATGL profile. Conclusions/interpretation: HSL, but not $A T G L$ gene expression shows a regulation according to obesity status and is associated with increased adipose tissue lipase activity. Moreover, HSL has a higher capacity than ATGL to hydrolyse triglycerides in vitro.

Keywords Adipocyte - ATGL · Catecholamines · Cos-7 cell $\cdot$ HSL $\cdot$ LIPE $\cdot$ Lipolysis $\cdot$ PNPLA2

Abbreviations ATGL: adipose triglyceride lipase - BAY: 4-isopropyl-3-methyl-2-[1-(3-(S)-methyl-piperidin-1-yl)methanoyl]-2H-isoxazol-5-one - CAT: chloramphenicol acetyl transferase - HSL: hormone-sensitive lipase · MOME: 1(3)-mono-oleyl-2-O-mono-oleylglycerol - PKA: protein kinase-A

\section{Introduction}

Alterations in adipocyte lipolysis are observed in several insulin-resistant conditions [1]. Hormone sensitive lipase (HSL, now known as LIPE), the product of LIPE, has long been considered to be the only rate-limiting step for adipocyte lipolysis [2]. This enzyme possesses tri- and diglyceride hydrolase activities and is regulated by the major lipolysis-regulating hormones, which in man are insulin, catecholamines and natriuretic peptides [3]. However, HSL knock-out mice have residual lipolytic activity $[4,5]$, which may be attributed to an additional lipase with high affinity for triglycerides [6, 7]. Accordingly, a novel adipocyte-specific lipase termed adipose triglyceride lipase (ATGL, now known as patatin-like phospholipase domain containing 2 [PNPLA2]), the product of Pnpla2, and alternatively designated $\mathrm{iPLA}_{2} \zeta$ or desnutrin, was recently identified using different strategies [8-10]. The murine ATGL-protein consists of 486 amino acids, whereas the corresponding human form is a 506-amino acid protein. 
Enzymatic analyses have shown that murine ATGL possesses significant triglyceride hydrolysing activity accompanied by diglyceride accumulation. Thus, it has been suggested that ATGL acts as an additional ratelimiting lipase, at least for lipolysis in mouse fat cells [9]. However, the functional importance of this novel lipase in human adipocytes remains to be established.

Using a selective inhibitor of HSL, we recently showed that in mouse and human adipocytes, catecholamineinduced lipolysis is mediated by HSL, whereas a non-HSL lipase contributes to basal lipolysis [11]. To gain further insight into the relative roles of $A T G L$ and $H S L$ in humans, we investigated their adipose tissue gene expression patterns in relation to obesity and lipolytic capacity. We also studied the relative contribution of the two enzymes to the in vitro hydrolysis of tri- and diglycerides.

\section{Subjects, materials and methods}

\section{Subjects}

In mRNA expression analyses, three separate cohorts were used including obese and lean men and women. All were healthy and free of medication and ate a standard Swedish diet. They were all living in the Stockholm area and were at least of second-generation Scandinavian origin. None was completely sedentary or involved in athletic performances and none had undergone a slimming programme or experienced a change in body weight $(>1 \mathrm{~kg})$ within 6 months before the study, according to self-report. The study was explained in detail to each subject and his or her informed consent was obtained. It was approved by the Hospital's committee on ethics.

Cohort 1 was composed of 80 obese (BMI $31-53 \mathrm{~kg} / \mathrm{m}^{2}$ ) and 16 lean (BMI 20-24 kg/m ${ }^{2}$ ) women. At about $07.30 \mathrm{~h}$ after an overnight fast, an adipose tissue sample (1-4 g) was obtained by needle biopsy from the abdominal subcutaneous area under local anaesthesia, as described [12]. This tissue was frozen in liquid nitrogen, kept frozen at $-70^{\circ} \mathrm{C}$ and used for subsequent mRNA analysis (see below). In obese subjects, adipose tissue was also available for fat cell lipolysis studies (see below).

Cohort 2 consisted of 67 obese (BMI $30.2-60.2 \mathrm{~kg} / \mathrm{m}^{2}$ ) and 26 non-obese (BMI 19.6-29.8 kg/m ${ }^{2}$ ) men and women undergoing laparoscopic weight reduction or gall stone surgery at the Department of Surgery, Karolinska University Hospital Huddinge, and from whom peroperative fat biopsies from omental and subcutaneous adipose tissue (1-2 g) were taken. In 13 of the obese women (cohort 3), a second subcutaneous fat biopsy was taken 2 to 4 years after surgery. Since with the exception of 13 subjects, cohorts 1 and 2 consisted of two separate sample groups, we were not able to perform simultaneous subcutaneous and omental mRNA analyses from the same individual. All cohort 2 subjects had stable weight after the weight reduction and their BMI had decreased by an average of $15 \mathrm{~kg} / \mathrm{m}^{2}$. All tissues were frozen in liquid nitrogen and used for subsequent mRNA and enzymatic analyses. At about
$07.30 \mathrm{~h}$ after an overnight fast, a venous blood sample was obtained for analysis of plasma levels of glucose, insulin, triglycerides, cholesterol and HDL cholesterol, which were performed by the hospital's accredited chemistry laboratory.

\section{Adipose tissue mRNA analysis}

Total RNA was extracted from $300 \mathrm{mg}$ of adipose tissue or differentiated preadipocytes using the RNeasy mini kit (Qiagen, Hilden, Germany). The RNA concentration and purity were assessed spectrophotometrically. A bioanalyser (Agilent 2100; Agilent Technologies, Kista, Sweden) was used to confirm the integrity of the RNA. From each sample, $1 \mu \mathrm{g}$ of total RNA was reverse-transcribed to cDNA using a kit (Omniscript RT; Qiagen) and random hexamer primers (Invitrogen, Tåstrup, Denmark). To minimise methodological errors due to variation in cDNA synthesis, it was performed simultaneously for all subjects included in the first, second and third cohorts, respectively, using exactly the same mix of primers and RT kit. In a final volume of $25 \mu \mathrm{l}, 5 \mathrm{ng}$ of cDNA was mixed with $2 \times$ SYBR green PCR master mix (Bio-Rad Laboratories, Hercules, CA, USA) and primers (Invitrogen). The primer pairs were selected to yield a single amplicon based on dissociation curves and analysis by agarose gel electrophoresis. The primers used were: 5'-GTGTCAGA CGGCGAGAATG-3' (sense) and 5'-TGGA GGGAGG GAGGGATG-3' (antisense) for ATGL; 5'-CTCAGTGTG CTCTCCAAGTG-3' (sense) and 5'-CACCCAGGCGG AAGTCTC-3' (antisense) for HSL; and 5'-TGACTCAA CACGGGAAACC-3' (sense) and 5'-TCGCTCCACCAA CTAAGAAC-3' (antisense) for 18S. Quantitative real-time PCR was performed in an iCycler IQ (Bio-Rad). The mRNA levels were determined by a comparative $C_{\mathrm{t}}$ method. The subject with the highest $C_{\mathrm{t}}$ value was used as a reference; all other $C_{\mathrm{t}}$ values for the target gene and reference gene, respectively, were subtracted from this $C_{\mathrm{t}}$ value. The $C_{\mathrm{t}}$ values were then normalised to $18 \mathrm{~S}$ rRNA using the formula $2^{\Delta \mathrm{C}_{\mathrm{t}}-\text { target gene }} / 2^{\Delta \mathrm{C}_{\mathrm{t}}-\text { reference gene }}$.

\section{Lipolysis studies}

One portion of adipose tissue $(\sim 1 \mathrm{~g})$ from obese subjects (cohort 1) was immediately subjected to collagenase treatment and isolated fat cells were incubated in duplicate exactly as described [13]. In brief, diluted cells were incubated in an albumin-containing buffer ( $\mathrm{pH} \mathrm{7.4)} \mathrm{for} 2 \mathrm{~h}$ at $37^{\circ} \mathrm{C}$ with air as gas phase without (basal) or with increasing concentrations of either the natural catecholamine noradrenaline, the selective beta- 1 adrenergic receptor agonist dobutamine or the selective beta- 2 adrenergic receptor agonist terbutaline. Glycerol release to the incubation medium was used as an index of lipolysis. As too few fat cells were available, experiments with noradrenaline, dobutamine and terbutaline were not performed 
in four (noradrenaline), three (dobutamine) and three (terbutaline) subjects from cohort 1 . In the remaining experiments we always obtained a maximum stimulation of glycerol release with the concentrations of adrenergic agonists used. Lipolysis data were expressed as either basal release of glycerol $/ 10^{7}$ cells or maximal agonist-induced minus basal release of glycerol $/ 10^{7}$ cells.

Transfection and expression of HSL and ATGL cDNA

Human HSL and ATGL cDNA were cloned into the pcDNA3 vector (InVitrogen). DNA sequencing was performed to check correct insertion of the cDNA using an ABI3100 automatic sequencer (Applied Biosystems, Courtaboeuf, France). Purified plasmids (Qiagen) were transfected into Cos-7 cells using lipofectamine (InVitrogen), following the recommendations of the manufacturer. To check transfection efficiency, pcDNA3-CAT (InVitrogen), an expression vector for the chloramphenicol acetyl transferase (CAT) gene, was co-transfected with the lipase expression vectors. Each construct was transfected in duplicate. Cells were collected $48 \mathrm{~h}$ post-transfection either in RLT buffer (Qiagen) for total RNA preparation or in homogenisation buffer $(0.25 \mathrm{~mol} / 1$ sucrose, $1 \mathrm{mmol} / 1$ EDTA, pH7.0, $1 \mathrm{mmol} / \mathrm{l}$ dithioerythritol, $20 \mu \mathrm{g} / \mathrm{ml}$ leupeptin, $20 \mu \mathrm{g} / \mathrm{ml}$ antipain) for enzymatic measurements. Protein concentrations were determined with Bio-Rad Protein Assay using bovine serum albumin as standard.

Total RNA was isolated using an RNeasy mini kit (Qiagen). Total RNA (1 $\mu \mathrm{g})$ was treated with DNase I (DNase I amplification grade; Invitrogen), then retrotranscribed using random hexamers and Supercript II reverse transcriptase (InVitrogen). Real-time quantitative PCR was performed using a sequence detection system (GeneAmp 7000; Applied Biosystems) and assays-ondemand for human HSL (Hs00943404) and human ATGL (Hs00982040) (Applied Biosystems). Quantitative measurements were obtained using PCR amplicons encompassing the cDNA regions amplified by the two assays-on-demand. Primer sequences were as follows: hATGLsens GGTGCCAAGTTCATTGAGGT, hATGLantisens 5'-AACTGGATGCTGGTGTTGGT-3'; hHSLsens 5'CTGCACAAATCCCGCTATG-3', hHSLantisens 5'-CACG TCCAGGTTCTGTGTGA-3'. Known quantities of amplicons were used to build a standard curve. Using the linear equation of the standard curves, the absolute amounts of $H S L$ or $A T G L$ mRNA were calculated from experimental $C_{\mathrm{t}}$ obtained by real-time PCR. 18S rRNA level was determined with the Ribosomal RNA Control Taqman Assay kit (Applied Biosystems).

Assays of lipase and chloramphenicol acetyl transferase activities

In vitro enzymatic activities were performed as described [14]. Briefly, 1(3)-mono-oleyl-2-O-mono-oleylglycerol (MOME) and triolein were emulsified with phospholipids by sonication. MOME is a diacylglycerol analogue. It allows measurement of diacylglycerol hydrolase activity and is not a substrate for monoacylglycerol lipase. Fatdepleted bovine serum albumin (Sigma-Aldrich) was used as a fatty acid acceptor. Cellular homogenates from transfected Cos-7 cells and human adipose tissue samples obtained as described above (Subjects) or during plastic surgery according to French law on bioethics were centrifuged at 18,000 $\mathrm{g}$ for $45 \mathrm{~min}$. Unless otherwise indicated, the $\mathrm{pH}$ of the reaction assay was 7.0. The supernatants were incubated for $30 \mathrm{~min}$ at $37^{\circ} \mathrm{C}$ with the different substrates. Hydrolysis was stopped and radiolabelled oleic acid released was measured using a scintillation counter (Tri-Carb 2100TR; Packard, Rungis, France). No triolein hydrolase activity activity was detected in Cos cells transfected with an empty vector (data not shown). To determine HSL-independent triglyceride lipase activity, we used the selective HSL inhibitor 4-isopropyl-3-methyl-2[1-(3-(S)-methyl-piperidin-1-yl)-methanoyl]-2H-isoxazol5-one (BAY) [11, 15]. CAT activity was determined on cellular extracts collected in lipase homogenisation buffer [16]. CAT activities were similar in lipase homogenisation

Table 1 Clinical data from subjects in cohorts 1 and 2

\begin{tabular}{lcccc}
\hline & \multicolumn{2}{c}{ Cohort 1 (subcutaneous) } & Cohort 2 (omental) \\
\cline { 2 - 3 } & Obese $(n=80)$ & Non-obese $(n=16)$ & Obese $(n=67)$ & Non-obese $(n=26)$ \\
\hline Sex (male/female) & $0 / 80$ & $0 / 16$ & $30 / 37$ & $2 / 24$ \\
Age (years) & $39 \pm 10$ & $38 \pm 9$ & $39 \pm 10$ & $42 \pm 11$ \\
BMI (kg/m ${ }^{2}$ ) & $39 \pm 6$ & $22 \pm 1$ & $42 \pm 6$ & $24 \pm 2$ \\
Waist (cm) & $117 \pm 13$ & $76 \pm 5$ & $128 \pm 13$ & $81 \pm 10$ \\
Plasma glucose (mmol/l) & $5.7 \pm 1.1$ & $4.7 \pm 0.3$ & $6.4 \pm 2.5$ & $4.9 \pm 0.5$ \\
Plasma insulin (mU/l) & $16 \pm 9$ & $5.4 \pm 1.5$ & $23 \pm 11$ & $8.0 \pm 2.9$ \\
Plasma triglycerides (mmol/l) & $1.4 \pm 0.7$ & $0.7 \pm 0.2$ & $2.2 \pm 1.4$ & $1.3 \pm 0.7$ \\
Plasma cholesterol (mmol/l) & $5.0 \pm 1.1$ & $4.7 \pm 0.7$ & $5.5 \pm 1.0$ & $5.3 \pm 1.1$ \\
Plasma HDL-cholesterol & $1.2 \pm 0.3$ & $1.7 \pm 0.4$ & $1.2 \pm 0.5$ & $1.4 \pm 0.3$ \\
Plasma NEFA (mmol/l) & $0.70 \pm 0.20$ & $0.67 \pm 0.25$ & $0.80 \pm 0.18$ & $0.64 \pm 0.18$ \\
\hline
\end{tabular}

Values are mean $\pm \mathrm{SD}$ 

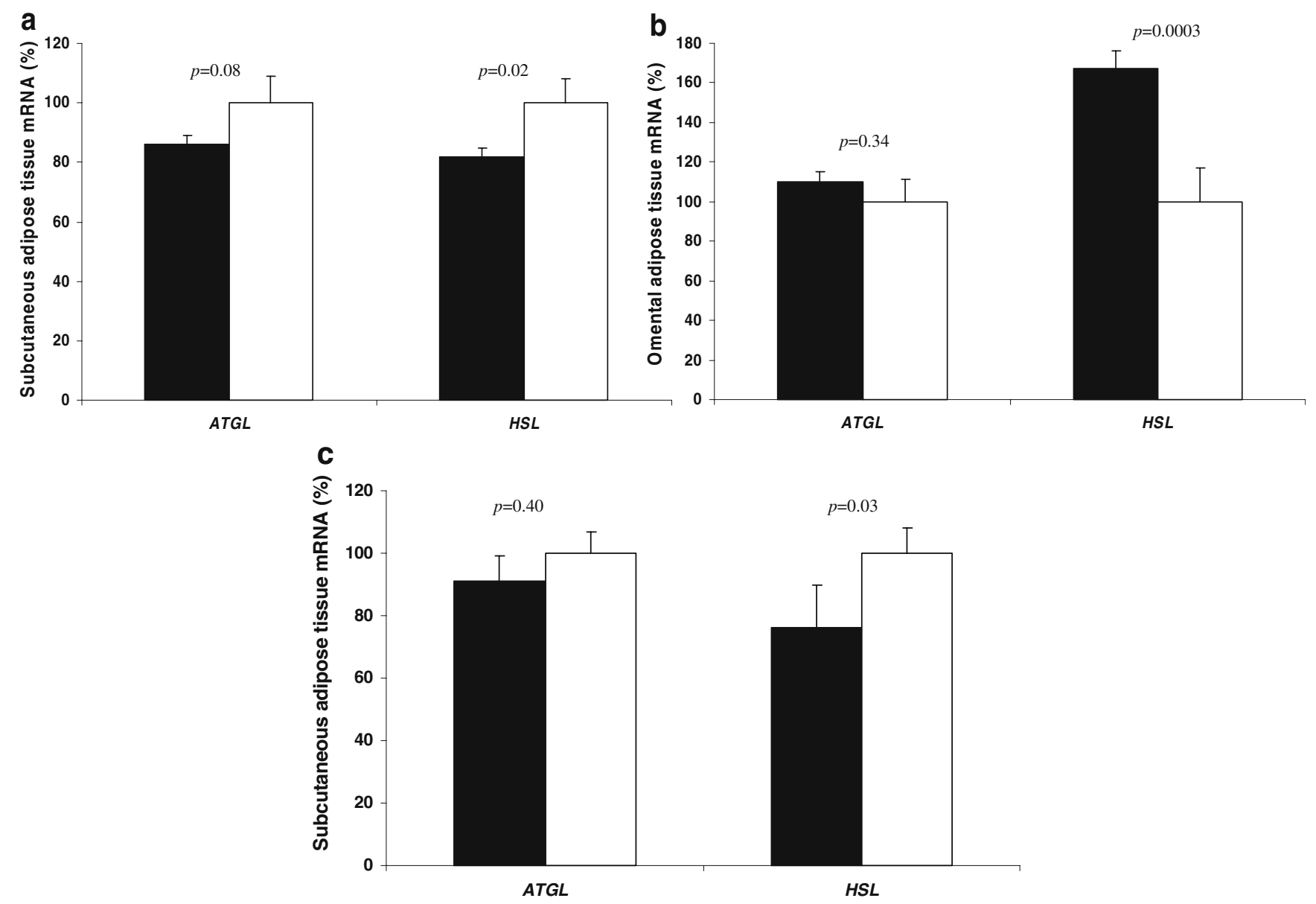

Fig. $1 A T G L$ and $H S L$ mRNA levels a in subcutaneous adipose tissue of obese $(n=80)$ and non-obese $(n=16)$ subjects, $\mathbf{b}$ in omental adipose tissue of obese $(n=67)$ and non-obese $(n=26)$ subjects, and $\mathbf{c}$ in subcutaneous adipose tissue before and after weight reduction

buffer and the conventionally used Tris-based buffer (data not shown).

\section{Statistical analysis}

Values are mean \pm SD or SEM. They were compared using Student's paired or unpaired $t$-test, ANOVA, analysis of one or two-sided covariance (ANCOVA) using BMI as covariate, and by linear regression analysis. A $p$ value of 0.05 or less was considered to be statistically significant. The analyses were performed using StatView version 6.0 (Stata, College Station, TX, USA).

\section{Results}

HSL and ATGL gene expression in obesity

Clinical data on subjects included in cohorts 1 and 2 are shown in Table 1. In Fig. 1, the influence of obesity (cohorts 1 and 2) on expression levels of $A T G L$ and $H S L$ mRNA is shown. There was no significant difference in
ATGL mRNA expression in subcutaneous or in omental adipose tissue between obese and non-obese subjects. In contrast, HSL mRNA expression in subcutaneous adipose tissue from obese subjects was reduced, whereas in omental tissue from the same group HSL mRNA levels were increased. Moreover, mRNA levels of subcutaneous $H S L$ only, but not of $A T G L$ were increased upon weight reduction (Fig. 1). The relation between omental adipose tissue mRNA of $A T G L$ and $H S L$ was analysed using linear

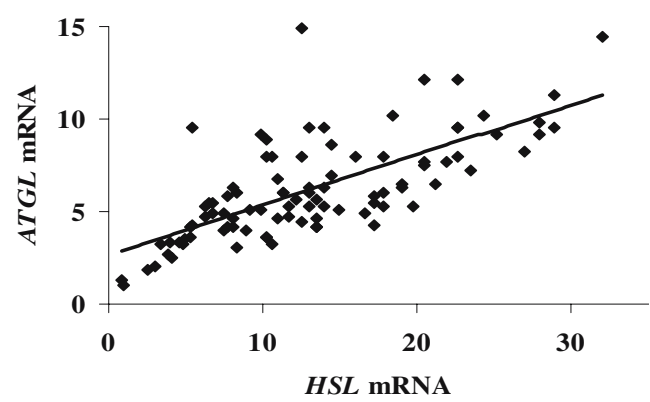

Fig. 2 Relationship between $A T G L$ and $H S L$ mRNA in omental adipose tissue from 93 obese and non-obese subjects using linear regression analysis. $r=0.71 ; p<0.0001$ 
regression (Fig. 2); the expression of the two genes was highly correlated.

HSL and ATGL mRNA levels in relation to lipolysis and lipase activity

We next divided the obese subjects $(n=80)$ of cohort 1 into tertiles of $H S L$ or $A T G L$ mRNA (high, intermediate, low) and compared the highest and lowest tertile (Table 2). Age did not differ significantly between these two tertiles (data not shown). However, there was a difference in BMI between high and low expression levels for $H S L$ mRNA. In subsequent analysis, therefore, data for both HSL and $A T G L$ mRNA were analysed using ANCOVA with BMI as an independent variable. Fat cell volume was negatively associated with $H S L$ mRNA but not with $A T G L$ mRNA. Results from lipolysis experiments in human fat cells showed a lower basal release of glycerol in subjects with a high expression level of both $H S L$ and $A T G L$. However, we found no relationship between the mRNA expression level of either $H S L$ or $A T G L$ and lipolytic capacity expressed as maximal minus basal lipolysis for noradrenaline, dobutamine or terbutaline.

To further explore the hypothesis that increased $H S L$ and $A T G L$ expression is related to lipid mobilisation of human fat tissue, we analysed lipase activity, determined as fatty acid release from triolein hydrolysis, in subcutaneous adipose tissue extracts from 28 subjects of cohort 1 . Subjects were divided into tertiles according to the level of fatty acid release and the high tertile group was compared to the low tertile group. As seen in Table 3, a high level of fatty acid release was associated with an increased in vitro maximal lipolytic activity for noradrenaline, dobutamine, and terbutaline (borderline significance). Moreover, subjects with increased lipase activity also had a higher level of $H S L$ mRNA, whereas no significant difference between the groups was found for $A T G L$ mRNA.
Table 3 Lipase activity in relation to fat cell lipolysis and $H S L$ and $A T G L$ mRNA expression

\begin{tabular}{|c|c|c|c|}
\hline & \multicolumn{2}{|l|}{ Lipase activity } & \multirow{2}{*}{$\begin{array}{l}p \\
\text { value }\end{array}$} \\
\hline & $\begin{array}{l}\text { High-activity } \\
\text { group }^{\text {a }}\end{array}$ & $\begin{array}{l}\text { Low-activity } \\
\text { group }^{b}\end{array}$ & \\
\hline BMI $\left(\mathrm{kg} / \mathrm{m}^{2}\right)$ & $40 \pm 6$ & $41 \pm 5$ & 0.80 \\
\hline Fat cell volume $(\mathrm{pl})$ & $838 \pm 153$ & $834 \pm 144$ & 0.83 \\
\hline $\begin{array}{l}\text { Basal lipolysis } \\
\left(\mu \mathrm{mol} \text { glycerol } / 10^{7} \text { cells }\right)\end{array}$ & $11.9 \pm 4.4$ & $11.1 \pm 10.5$ & 0.68 \\
\hline \multicolumn{4}{|l|}{$\begin{array}{l}\text { Maximal-basal lipolysis } \\
\left(\mu \mathrm{mol} \text { glycerol } / 10^{7} \text { cells }\right)\end{array}$} \\
\hline Noradrenaline & $16.7 \pm 6.5$ & $13.1 \pm 5.9$ & 0.05 \\
\hline Dobutamine & $24.3 \pm 7.8$ & $19.9 \pm 7.4$ & 0.05 \\
\hline Terbutaline & $25.1 \pm 7.2$ & $21.8 \pm 5.8$ & 0.06 \\
\hline$H S L$ mRNA/ $18 S$ rRNA & $4.4 \pm 1.5$ & $3.3 \pm 1.3$ & 0.02 \\
\hline$A T G L$ mRNA $/ 18 S$ rRNA & $4.9 \pm 1.5$ & $4.3 \pm 1.5$ & 0.21 \\
\hline
\end{tabular}

Samples were divided into tertiles (high, intermediate, low) according to the lipase activity measured in adipose tissue samples. Triolein was used as a substrate. High and low activity groups were analysed. Values are mean $\pm \mathrm{SD}$ and were compared using one-tailed ANCOVA with BMI as a covariate

${ }^{a}$ High activity group: $0.56 \pm 0.07 \mathrm{nmol} \mathrm{min}{ }^{-1} \mathrm{mg}^{-1}$ protein $(n=10)$

${ }^{b}$ Low activity group: $0.32 \pm 0.04 \mathrm{nmol} \mathrm{min}^{-1} \mathrm{mg}^{-1}$ protein $(n=10)$

HSL and ATGL glyceride hydrolase activities

HSL and ATGL both possess triglyceride hydrolase activity $[9,10,17]$. We wished to determine the relative contribution of the two enzymes to the in vitro hydrolysis of triolein. Expression vectors for human HSL and ATGL were transfected into Cos-7 cells. Transfection efficiency evaluated by CAT activities was similar for the two constructs (data not shown). The HSL and ATGL mRNA levels were $88 \pm 1$ and $146 \pm 1 \mathrm{amol} / \mu \mathrm{g}$ total RNA, respectively $(n=3)$. There was no difference in $18 \mathrm{~S}$ rRNA levels. Despite higher $A T G L$ mRNA expression, the enzyme showed much lower hydrolase activity than HSL

Table 2 Gene expression in relation to human subcutaneous fat cell lipolysis

\begin{tabular}{|c|c|c|c|c|c|c|c|}
\hline \multirow[t]{2}{*}{ mRNA } & \multirow[t]{2}{*}{ Group } & \multirow[t]{2}{*}{ BMI $\left(\mathrm{kg} / \mathrm{m}^{2}\right)$} & \multirow[t]{2}{*}{ Fat cell volume $(\mathrm{pl})$} & \multirow{2}{*}{$\begin{array}{l}\text { Basal lipolysis } \\
\left(\mu \mathrm{mol} \text { glycerol } / 10^{7} \text { cells }\right)\end{array}$} & \multicolumn{3}{|c|}{ Maximal-basal lipolysis $\left(\mu \mathrm{mol} / 10^{7}\right)$} \\
\hline & & & & & Noradrenaline & Dobutamine & Terbutaline \\
\hline \multirow[t]{3}{*}{$H S L$} & $\begin{array}{l}\text { High expression } \\
(6.2 \pm 0.7) n=27\end{array}$ & $37 \pm 5$ & $790 \pm 127$ & $9.6 \pm 5.3$ & $13 \pm 8$ & $20 \pm 10$ & $22 \pm 10$ \\
\hline & $\begin{array}{l}\text { Low expression } \\
(2.9 \pm 0.7) n=27\end{array}$ & $42 \pm 6$ & $901 \pm 134$ & $14.3 \pm 7.3$ & $14 \pm 8$ & $22 \pm 11$ & $23 \pm 11$ \\
\hline & $p$ value & 0.0007 & 0.003 & 0.01 & 0.55 & 0.56 & 0.54 \\
\hline \multirow[t]{3}{*}{$A T G L$} & $\begin{array}{l}\text { High expression } \\
(7.3 \pm 1.0) n=27\end{array}$ & $38 \pm 5$ & $825 \pm 139$ & $9.8 \pm 5.4$ & $15 \pm 7$ & $20 \pm 7$ & $22 \pm 6$ \\
\hline & $\begin{array}{l}\text { Low expression } \\
(3.8 \pm 0.8) n=26\end{array}$ & $41 \pm 5$ & $886 \pm 135$ & $14.4 \pm 8.4$ & $14 \pm 5$ & $19 \pm 7$ & $21 \pm 6$ \\
\hline & $p$ value & 0.053 & 0.11 & 0.01 & 0.63 & 0.76 & 0.86 \\
\hline
\end{tabular}

Subjects were divided into tertiles (high, intermediate, low) according to the relative expression of $H S L$ or $A T G L$ mRNA expressed as arbitrary units. High and low expression groups were analysed. Values are mean \pm SD and were compared using two-tailed ANCOVA with BMI as covariate 
(Fig. 3a). When cellular extracts from HSL- and ATGLtransfected cells were combined, the total activity corresponded to the sum of individual hydrolase activities (Fig. 3b). Hence, there is no evidence in vitro of a synergistic effect of the two enzymes on hydrolysis of triglycerides.

As previously shown [11], BAY completely inhibits HSL-mediated triglyceride hydrolase activity, but it had no effect on ATGL (Fig. 4a). When the two enzymes were combined, the residual activity after inhibition by BAY corresponded to ATGL activity. Diglyceride hydrolase activity was determined using MOME, a diacylglycerol analogue with only one hydrolysable ester bond (Fig. 4b). HSL shows robust diglyceride hydrolase activity that is approximately ten times higher than its activity towards triglycerides. Addition of BAY completely inhibited HSLmediated diglyceride hydrolase activity (data not shown). ATGL was devoid of any diglyceride hydrolase activity.

The low activity of ATGL compared to HSL may be due to suboptimal $\mathrm{pH}$ conditions. Triolein hydrolase activity was determined at various $\mathrm{pH}$ levels (Fig. 5). As previously reported, the optimal $\mathrm{pH}$ for HSL is around 7 [17]. ATGL showed $50 \%$ less activity at $\mathrm{pH} 6$ than at $\mathrm{pH} 7$. The activity at $\mathrm{pH} 8$ was slightly higher. Interestingly, the $\mathrm{pH}$ profile of human white adipose tissue triolein hydrolase activity is identical to that of HSL and differs from the ATGL profile.

\section{Discussion}

The recently discovered $A T G L$ (iPLA $2 \zeta$, desnutrin) is abundantly expressed in adipose tissue of both mice and humans [9]. We have recently demonstrated that subcutaneous adipose tissue $A T G L$ expression levels are strongly correlated to the levels of HSL [11]. Here, we confirm this finding by showing a high level of correlation between $A T G L$ and $H S L$ expression in omental adipose tissue as well, suggesting that the expression of the two lipases may be tightly co-regulated in humans. However, the present findings also identify clear differences in the regulation of the two lipases. We have previously observed that $H S L$ expression in subcutaneous adipose tissue of obese subjects was decreased, correlating with low lipolytic effect of catecholamines [18]. This finding is supported by the present observation that HSL mRNA expression is lower in subcutaneous adipose tissue of obese subjects than in that of non-obese subjects, and that $H S L$ expression is increased after weight reduction. In contrast, we failed to demonstrate a corresponding effect of body weight on $A T G L$ expression. Moreover, omental adipose tissue of obese subjects showed increased levels of HSL mRNA only. This corresponds with previous findings of an increased lipolytic effect of catecholamines in visceral fat cells of obese subjects [19]. Altogether, these findings not only suggest that nutritional status has a divergent influence on expression levels of the two lipases, but also indicate putative species differences, given the demonstration of induced Atgl expression after fasting and glucocorticoid administration in mice [8]. As the present study material consists of a limited number of male subjects, it remains to be established whether a subject's sex influences the expression levels of $H S L$ and $A T G L$.

It has previously been demonstrated that high $H S L$ expression is related to a high lipolytic effect of catecholamines [20]. Here, we failed to demonstrate a relation between subcutaneous adipose tissue mRNA expression levels of $H S L$ and $A T G L$ on the one-hand, and fat cell maximal lipolytic activity expressed as maximal minus basal lipolysis on the other hand. However, in analysing subcutaneous adipose tissue lipase activity, we found that an increased level of fatty acid release from triolein hydrolysis was associated both with increased lipolytic activity and levels of HSL mRNA, but not with $A T G L$ mRNA, suggesting a predominant role of HSL in human fat cell lipid mobilisation.

The ultimate lipolytic capacity of HSL and ATGL is determined by their capacity to hydrolyse glycerides. We therefore analysed the triglyceride and diglyceride hydrolase activities of both HSL and ATGL using transfected Cos-7 cells. We found that HSL has a higher capacity than ATGL to hydrolyse triglycerides in vitro. In contrast to HSL, ATGL is devoid of diglyceride hydrolase activity. In vitro, HSL hydrolyses monoglycerides at the same rate as triglycerides [17]. Accordingly, incubation of a lipid

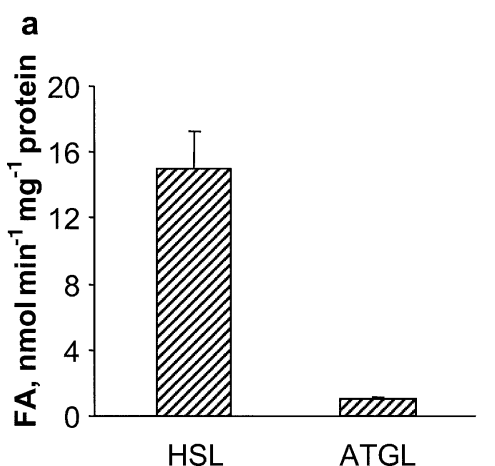

Fig. 3 Hydrolysis of triolein by human HSL and ATGL (a). Cos-7 cells were transfected with pcDNA3 vectors coding for human HSL or human ATGL. Enzymatic activity expressed as fatty acid (FA) release was measured on cellular extracts. Values are means \pm SEM of four independent experiments. b Effect of combined fractions of

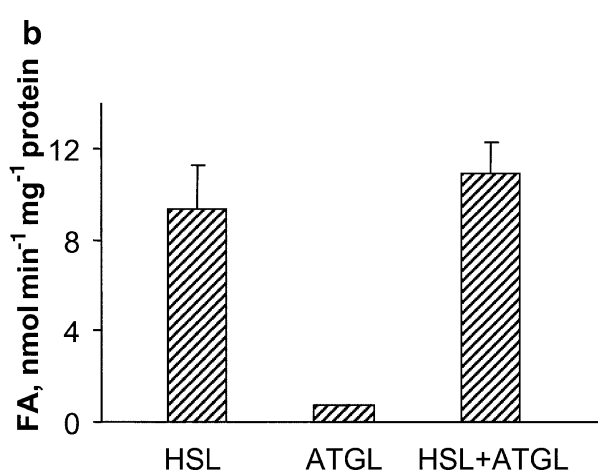

HSL and ATGL on the hydrolysis of triolein. Cos-7 cells were transfected as for (a). Enzymatic activity expressed as FA release was measured on a combination of similar amounts of cellular extract proteins from the different cell transfections. Values are means \pm SEM of three independent experiments 
a

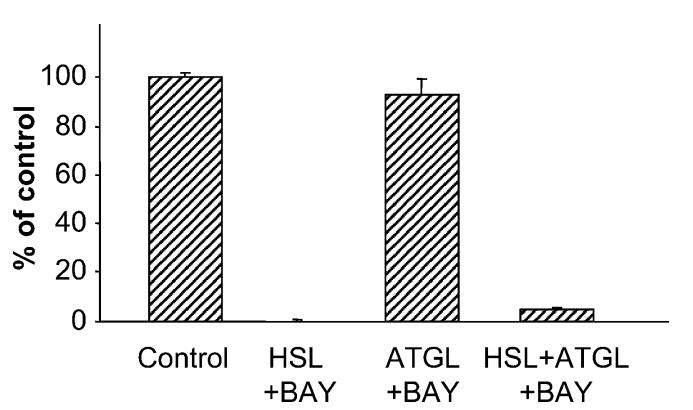

b

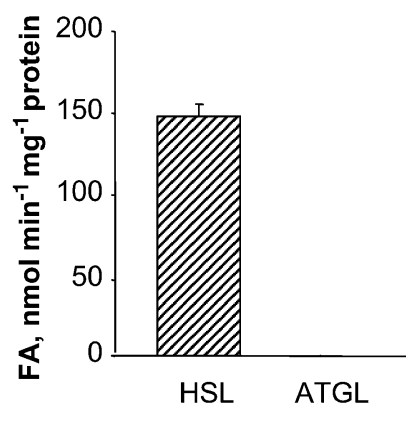

Fig. 4 Inhibition of HSL and ATGL triolein hydrolysis by the specific HSL inhibitor BAY (a). Cos-7 cells were transfected with pcDNA3 vectors coding for human HSL or human ATGL. Enzymatic activity expressed as fatty acid $(F A)$ release was measured on cellular extracts in the presence or absence of $1 \mu \mathrm{mol} / 1 \mathrm{BAY}$. Values expressed as percentage of lipase activity in

emulsion with HSL results in no accumulation of diglycerides and monoglycerides [21]. Therefore, HSL in vitro is able to release three molecules of fatty acids per molecule of triglyceride, compared to only one for ATGL. As the fatty-acid-releasing activity of HSL was about 15 fold higher than that of ATGL, it can be deduced that HSL has a five-fold higher triglyceride hydrolase activity than ATGL.

Zimmermann et al. suggested that ATGL was predominantly responsible for the initial step of triglyceride hydrolysis [9]. In support of this model, the authors reported that extracts containing HSL and ATGL showed twice the sum of the individual activities. We found no evidence for such a synergistic effect. Combination of cellular extracts and use of the HSL-specific inhibitor BAY indicated a purely additive effect. The reason for the discrepancy remains elusive, as the experimental conditions seem very similar. It is possible that yet unidentified cofactors for lipase activity are subject to species variation.

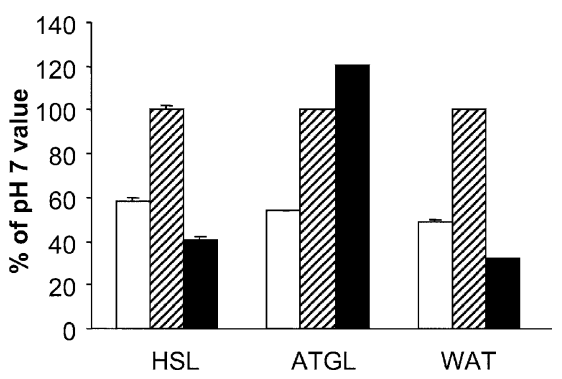

Fig. $5 \mathrm{pH}$ dependency of triolein hydrolysis by HSL, ATGL and human white adipose tissue (WAT). Cos-7 cells were transfected with pcDNA3 vectors coding for human HSL or human ATGL. Cellular extracts were prepared from human subcutaneous abdominal WAT. Enzymatic activity expressed as fatty acid release was measured on reaction buffer adjusted at different $\mathrm{pH}$. Values expressed as percentage of activity at $\mathrm{pH} 7$ are means \pm SEM of three independent experiments. Open bars, $\mathrm{pH}$ 6; hatched bars, $\mathrm{pH} 7$; filled bars, $\mathrm{pH} 8$ the absence of BAY are means \pm SEM of four independent experiments. b Human HSL and ATGL diglyceride hydrolase activity. Cos-7 cells were transfected as for (a). Diglyceride hydrolase activity expressed as FA release was measured on cellular extracts using the diacylglycerol analogue MOME. Values are means \pm SEM of three independent experiments

The low in vitro triglyceride hydrolase activity of ATGL could come from a suboptimal $\mathrm{pH}$ in our assay conditions. Indeed, other adipose tissue lipases such as lipoprotein lipase and monoglyceride lipase show a $\mathrm{pH}$ optimum of 8 in vitro $[22,23]$. ATGL had a slightly higher activity at $\mathrm{pH}$ 8 than at $\mathrm{pH} 7$, indicating a rather broad $\mathrm{pH}$ optimum. Interestingly, the $\mathrm{pH}$ profile of human adipose tissue extracts is much closer to the profile of HSL than to that of ATGL. This is another piece of evidence that HSL plays a predominant role in triglyceride hydrolysis.

These data further support our hypothesis on the respective role of HSL and ATGL in human adipose tissue lipolysis [11]. Stimulation of the catecholamine and natriuretic peptide pathways leads to the protein kinase-A (PKA)- and cGMP-dependent kinase (PKG)-dependent phosphorylation of HSL and hydrolysis of triglycerides by the enzyme. ATGL, the activity of which is not regulated by phosphorylation by PKA, may instead participate in the hydrolysis of triglycerides under basal conditions. HSL ensures the hydrolysis of diglycerides, a step that is not under hormonal control, occurring at a much higher rate than the hydrolysis of triglycerides. Although HSL has the capacity to hydrolyse monoglycerides in vitro, monoglyceride lipase is required to obtain complete hydrolysis of monoglycerides in vivo [24]. Rodents show marked differences in the regulation of lipolysis at the receptor level, e.g. a strong lipolytic effect of adrenocorticotropic hormone and lack of effect of natriuretic peptides $[1,3,25]$. Therefore, it cannot be ruled out that the respective roles of HSL and ATGL differ between rodents and humans.

To conclude, in comparing human adipose tissue gene expression of the LIPE gene product HSL and the PNPLA2 gene product ATGL, we found evidence of a downregulation by body fat and of association with in vitro hydrolysis of triolein for HSL only. Moreover, our data suggest that HSL plays a predominant role as both a tri- and diglyceride-hydrolysing lipase in human adipocytes. 
Acknowledgements This study was supported by grants from the Swedish Research Council, the French Programme for Research in Human Nutrition (PRNH), the Swedish Medical Society, the Swedish Heart and Lung Foundation, the Swedish Diabetes Association, the Foundation of Thuring, the European Foundation for the Study of Diabetes and the Novo Nordisk Foundation. This work is also part of the project 'Hepatic and adipose tissue and functions in the metabolic syndrome' (HEPADIP, see http://www.hepadip.org/), which is supported by the European Commission as an integrated project under the 6th Framework Programme (Contract LSHM-CT2005-018734).

\section{References}

1. Large V, Arner P (1998) Regulation of lipolysis in humans. Pathophysiological modulation in obesity, diabetes, and hyperlipidaemia. Diabetes Metab 24:409-418

2. Holm C (2003) Molecular mechanisms regulating hormonesensitive lipase and lipolysis. Biochem Soc Trans 31:11201124

3. Langin D, Lucas S, Lafontan M (2000) Millennium fat-cell lipolysis reveals unsuspected novel tracks. Horm Metab Res 32:443-452

4. Osuga J, Ishibashi S, Oka T et al (2000) Targeted disruption of hormone-sensitive lipase results in male sterility and adipocyte hypertrophy, but not in obesity. Proc Natl Acad Sci USA 97:787-792

5. Wang SP, Laurin N, Himms-Hagen J et al (2001) The adipose tissue phenotype of hormone-sensitive lipase deficiency in mice. Obes Res 9:119-128

6. Okazaki H, Osuga J, Tamura Y et al (2002) Lipolysis in the absence of hormone-sensitive lipase: evidence for a common mechanism regulating distinct lipases. Diabetes 51:3368-3375

7. Haemmerle G, Zimmermann R, Hayn M et al (2002) Hormonesensitive lipase deficiency in mice causes diglyceride accumulation in adipose tissue, muscle, and testis. J Biol Chem 277:4806-4815

8. Villena JA, Roy S, Sarkadi-Nagy E, Kim KH, Sul HS (2204) Desnutrin, an adipocyte gene encoding a novel patatin domaincontaining protein, is induced by fasting and glucocorticoids: ectopic expression of desnutrin increases triglyceride hydrolysis. J Biol Chem 279:47066-47075

9. Zimmermann R, Strauss JG, Haemmerle G et al (2004) Fat mobilization in adipose tissue is promoted by adipose triglyceride lipase. Science 306:1383-1386

10. Jenkins CM, Mancuso DJ, Yan W, Sims HF, Gibson B, Gross RW (2004) Identification, cloning, expression, and purification of three novel human calcium-independent phospholipase A2 family members possessing triacylglycerol lipase and acylglycerol transacylase activities. J Biol Chem 279:48968-48975
11. Langin D, Dicker A, Tavernier G et al (2005) Adipocyte lipases and defect of lipolysis in human obesity. Diabetes 54:3190 3197

12. Kolaczynski JW, Morales LM, Moore JH et al (1994) A new technique for biopsy of human abdominal fat under local anaesthesia with lidocaine. Int J Obes Relat Metab Disord 18:161-166

13. Ryden M, Faulds G, Hoffstedt J, Wennlund A, Arner P (2002) Effect of the (C825T) Gbeta(3) polymorphism on adrenoceptormediated lipolysis in human fat cells. Diabetes 51:1601-1608

14. Holm C, Olivecrona G, Ottosson M (2001) Assays of lipolytic enzymes. In: Ailhaud G (editor) Methods in molecular biology. Humana, Totowa, pp 97-119

15. Lowe DB, Magnuson S, Qi N et al (2004) In vitro SAR of (5(2H)-isoxazolonyl) ureas, potent inhibitors of hormone-sensitive lipase. Bioorg Med Chem Lett 14:3155-3159

16. Ausubel FM, Brent R, Kingston RE et al (1996) Current protocols in molecular biology. New York, Wiley

17. Fredrikson G, Strålfors P, Nilsson NÖ, Belfrage P (1981) Hormone-sensitive lipase of rat adipose tissue. Purification and some properties. J Biol Chem 256:6311-6320

18. Large V, Reynisdottir S, Langin D et al (1999) Decreased expression and function of adipocyte hormone-sensitive lipase in subcutaneous fat cells of obese subjects. J Lipid Res 40:2059-2066

19. Lonnqvist F, Thome A, Nilsell K et al (1995) A pathogenic role of visceral fat beta 3-adrenoceptors in obesity. J Clin Invest. 95:1109-1116

20. Large V, Arner P, Reynisdottir S et al (1998) Hormone-sensitive lipase expression and activity in relation to lipolysis in human fat cells. J Lipid Res 39:1688-1695

21. Raclot T, Holm C, Langin D (2001) A role for hormonesensitive lipase in the selective mobilization of adipose tissue fatty acids. Biochim Biophys Acta 1532:88-96

22. Tornqvist H, Belfrage P (1976) Purification and some properties of a monoacylglycerol-hydrolyzing enzyme of rat adipose tissue. J Biol Chem 251:813-819

23. Bengtsson G, Olivecrona T (1982) On the $\mathrm{pH}$ dependency of lipoprotein lipase activity. Biochim Biophys Acta 712:196-199

24. Fredrikson G, Tornqvist H, Belfrage P (1986) Hormonesensitive lipase and monoacylglycerol lipase are both required for complete degradation of adipocyte triacylglycerol. Biochim Biophys Acta 876:288-293

25. Sengenes C, Zakaroff-Girard A, Moulin A et al (2002) Natriuretic peptide-dependent lipolysis in fat cells is a primate specificity. Am J Physiol Regul Integr Comp Physiol 283: R257-265 